\title{
Modelling mixing and circulation in subglacial Lake Vostok, Antarctica
}

\author{
Malte Thoma $^{1,2}$, Klaus Grosfeld ${ }^{1}$, Christoph Mayer ${ }^{2}$ \\ 1 Alfred Wegener Institute for Polar and Marine Research, Bussestrasse 24, 27570 \\ Bremerhaven, Germany \\ 2 Bayerische Akademie der Wissenschaften, Kommission für Glaziologie, 80539 \\ München, Germany
}

Received: March 21, 2007 / Revised version: March 27, 2008

\begin{abstract}
Lake Vostok, isolated from direct exchange with the atmosphere by about $4 \mathrm{~km}$ of ice for millions of years, provides a unique environment. This inaccessibility raises the importance of numerical models to investigate the physical conditions within the lake. Using a three-dimensional numerical model and the best available geometry, we test different parameter settings to define a standard model configuration suitable for studying flow in this subglacial lake. From our model runs we find a baroclinic circulation within the lake that splits into three different parts: Along a topographic ridge in the northern part of Lake Vostok, bottom water masses are transported eastward, diverging away from the ridge. In the lake's surface layer, the flow in these two vertical overturning cells has opposite directions. In the southern part of the lake, where freezing occurs across about $3,500 \mathrm{~km}^{2}$, two opposing gyres split the water column vertically. The general flow is stronger in the southern basin with horizontal velocities in the order of $1 \mathrm{~mm} / \mathrm{s}$. The strongest upwelling, found in the eastern part of this basin, is about $25 \mu \mathrm{m} / \mathrm{s}$. We estimate the lower limit of the overturning timescale to be about 2.5 years vertically and 8.6 years horizontally. The basal mass loss of ice from the ice sheet floating on the lake is $5.6 \mathrm{~mm} /$ year (equivalent to a fresh water flux of $2.78 \mathrm{~m}^{3} / \mathrm{s}$, or a basal ice loss of $0.09 \mathrm{~km}^{3} /$ year). This imbalance indicates either a constant growth of the lake or its continuous (or periodical) discharge into a subglacial drainage system.
\end{abstract}

\section{Introduction}

Lake Vostok lies in the heart of the Antarctic continent hidden beneath $4 \mathrm{~km}$ of ice and extends over an area of about $15,000 \mathrm{~km}^{2}$. The lake has been covered by the vast East Antarctic Ice Sheet for up to 25 million years 
(Duxbury et al., 2001). The remote location and the thick ice cover make direct access to the lake difficult. The biological environment within the lake is assumed to be unique, and plans are being developed to penetrate the lake without contaminating it (Siegert, 2005). Reliable knowledge of the circulation within the lake is required to decide, e.g., on the most suitable drill location or sampling strategy, optimising the scientific return of expensive drilling. Numerical models provide the only means of investigating the lake's environment prior to sampling. Basic early estimates of the lake's circulation suffered from the use of several poorly constrained parameters and questionable parametrisations (Wüest and Carmack, 2000; Walsh, 2002). These studies predicted contradictory flow directions and can only be seen as qualitative assessments.

More sophisticated three-dimensional numerical models were used by Williams (2001) and Mayer et al. (2003) to calculate the lake's circulation solving the full set of (so called) primitive equations (Bryan, 1969; Cox, 1984; Cox and Bryan, 1984). However, the model results are unrealistic because of the simplified or crude bathymetry of Lake Vostok that was available at that time (Fig.,1a). Williams (2001) pointed out the importance of a realistic water column thickness, because more effective warming of shallower regions due to geothermal heat flux leads to a varying horizontal density structure, and therefore, to baroclinic flow.

During the last few years, a wealth of information about the physiography and the physical conditions of Lake Vostok has been gathered. According to these new findings (Studinger et al., 2004), Lake Vostok is separated into two sub-basins by a shallow ridge of about $20 \mathrm{~km}$ in width, reducing the water column thickness to about $250 \mathrm{~m}$. The southern basin has a water column thickness of up to $870 \mathrm{~m}$ while the northern basin is somewhat shallower with water column depths not exceeding $500 \mathrm{~m}$ (Fig. 1b). The ice sheet above the lake exceeds thicknesses of $3,500 \mathrm{~m}$ in the south, where the Russian research station is located, and $4,300 \mathrm{~m}$ in the north. The ice sheet flow over the lake is directed mainly from west to east with a weak divide diverting the flow slightly from its main direction at roughly $77^{\circ} \mathrm{S}$ (Pattyn et al., 2004).

In this study, the new bathymetry and a more recent ice draft is used as the geometric boundary condition for the model domain in an improved version of the model used by Mayer et al. (2003). With this model, we systematically investigate the sensitivity of the flow regime to the parametrisation of horizontal and vertical mixing, as well as the impact of the Prandtl number. The aim is to define a set of parameters that is suitable for modeling subglacial lakes and which can be used as a basis for further studies.

After introducing the model setup in Section 2, we describe, in Section 3.1, the impact of different values for viscosity and diffusion to the model results. The sensitivities to horizontal and vertical Prandtl numbers are discussed in Section 3.2. Based on these experiments, we define a standard model configuration and discuss the flow pattern, basal mass balance 
and temperature distribution of Lake Vostok in Section 3.3. Discussion of the results and conclusions are given in the last section (Section 4).

\section{Theoretical model and setup}

We use the three-dimensional fluid dynamics model Rombax (Thoma et al., 2006a), which is a revised version of a $\sigma$-coordinate ocean model based on Gerdes (1993) and Grosfeld et al. (1997). Improvements with respect to Thoma et al. (2006a) include an equation of state which is suitable for low (or zero) salinities under high pressure (Jackett and McDougall, 1995), a linearised form of the pressure- and salinity-dependent freezing point temperature based on Fofonoff and Millard (1983), geothermal heating and thermal conduction into the floating ice in melting areas only. Based on the interpretation of satellite magnetic data for the Lake Vostok area (Maule et al., 2005), the model uses an average geothermal heat flux of $54 \mathrm{~mW} / \mathrm{m}^{2}$. Thermal heat flux into the ice $\left(33 \mathrm{~mW} / \mathrm{m}^{2}\right)$ is estimated from the difference between the annual mean surface and the basal freezing-point temperatures, heat conductivity and mean ice thickness (Mayer et al., 2003). Compared to earlier Lake Vostok modelling studies (Williams, 2001; Mayer et al., 2003), we increased the horizontal resolution to $0.1^{\circ} \times 0.05^{\circ}$ (about $2.5 \mathrm{~km}$ in longitude and $5.5 \mathrm{~km}$ in latitude) and the vertical resolution to $16 \sigma$-layers (with a layer thickness varying from 3 to $43 \mathrm{~m}$ ). Preceding studies have shown that this layer number offers a good compromise between computational cost and a good representation of the bathymetry and suppresses numerical artifacts in the model (Weaver and Sarachik, 1990)

To reduce artificial diapycnal mixing and pressure gradient errors in $\sigma$-coordinate ocean models with steep slopes, spatial filtering is a useful tool (e.g., Ezer and Mellor, 1997; Ly and Jiang, 1999; Thoma et al., 2006a,b). In contrast to regional ocean models, where continental shelf breaks in the interior of the model domain represent the strongest depth gradients, the steepest slopes in Lake Vostok are located at it's edges, where the water column thickness reaches a minimum. Preceding studies have shown that filtering of these rough topographic features has only a minor impact on the modelled results and, hence, can be omitted. Owing to lower density gradients and low flow velocities in Lake Vostok compared to the open ocean, the impact of the pressure gradient error on the modelled flow velocity rises to about $1 \%$, but has no impact on the modelled features presented in this study.

Subgridscale processes, such as molecular viscosity and diffusion, cannot be resolved by large-scale models. Hence, friction and diffusion have to be parametrised by eddy coefficients to account for subgridscale processes and to maintain the model's numerical stability. In general, terrain-following ocean models work best with as little along- $\sigma$ viscosity (and diffusion) as possible. This is to minimise diapycnal mixing (Ezer and Mellor, 2004). In the specific case of subglacial lakes, where advection is very small, underestimated viscosities do not result in numerical instabilities at first; instead, 
they generate physically unrealistic noisy flow and temperature patterns. On the other hand, overestimated eddy viscosities erode small-scale processes and result in over-smoothed fields. An estimation of the horizontal eddy viscosity for momentum, based on the order of magnitude of the lake's dimension $L$ and advection velocity $v$, leads to

$$
A_{h}^{M}=\frac{L \times v}{2} \approx \frac{100 \mathrm{~km} \times 1 \frac{\mathrm{mm}}{\mathrm{s}}}{2}=50 \frac{\mathrm{m}^{2}}{\mathrm{~s}},
$$

a value chosen by Mayer et al. (2003). In this study we investigate variations of $A_{h}^{M}$ from 1 to $100 \mathrm{~m}^{2} / \mathrm{s}$. Due to different scaling of the (anisotropic) horizontal and vertical dimensions in fluid dynamics models, the vertical eddy viscosity is much smaller. Mayer et al. (2003) chose a factor of $10^{-6}$, leading to $A_{v}^{M}=A_{h}^{M} \times 10^{-6}=5 \times 10^{-5} \mathrm{~m}^{2} / \mathrm{s}$. We apply this factor as well as testing the results of using values of $2 \times 10^{-6}$ and $4 \times 10^{-6}$. Numerically, the implemented diffusion scheme acts along and perpendicular to $\sigma$ coordinates, rather than horizontally and vertically. But according to earlier studies (Mellor and Blumberg, 1985), this is sufficient as long as the layer slope is not too steep.

Beside viscosity (or diffusion of momentum), diffusion of temperature (or, in the more general case, tracers) must also be parametrised. The horizontal and the vertical Prandtl numbers are dimensionless numbers, defined as the ratio of momentum diffusivity and thermal diffusivity:

$$
\operatorname{Pr}^{h}=\frac{A_{h}^{M}}{A_{h}^{H}}, \quad \operatorname{Pr}^{v}=\frac{A_{v}^{M}}{A_{v}^{H}} .
$$

They describe the characteristics of a fluid with respect to the dominance of advection $(\operatorname{Pr}>1)$ or thermal conduction $(\operatorname{Pr}<1)$. In ocean modelling, a range of (horizontal) Prandtl numbers from 1 (e.g., Ezer and Mellor, 2000) to 10 (e.g., Cox and Bryan, 1984) is used. To test the entire reasonable parameter space, we vary $\operatorname{Pr}^{h}$ in our first experiments from 0.2 to 10 and keep $\operatorname{Pr}^{v}$ identical to $\operatorname{Pr}^{h}$. In a second set of experiments, we keep the horizontal Prandtl number $\operatorname{Pr}^{h}$ at unity and vary $P r^{v}$ within the same range as before.

\section{Results}

We start the model integration from a lake at rest with homogeneous initial conditions of fresh water and a temperature of $-2.6^{\circ} \mathrm{C}$, which is just above the pressure melting point of the shallowest lake region. For all experiments, the model is integrated for 150 years to reach a steady state.

\subsection{Subgridscale mixing with constant coefficients}

To investigate the impact of different mixing coefficients on the flow within subglacial Lake Vostok, we define distinct characteristic quantities that 
adequately reflect the modifications. These are the freezing area at the ice-lake interface, the maximum and the minimum temperature of the upper boundary layer, and the mean turbulent kinetic energy, defined as $T K E=\sum_{i} V_{i}\left(u_{i}^{2}+v_{i}^{2}\right) /(2 V)$, where $i$ is the grid box index, $u$ and $v$ are the zonal and meridional velocities and $V=\sum_{i} V_{i}$ the volume of the water body. Fig. 2 shows the impact of different eddy viscosity values on these quantities. With increasing viscosity, the freezing area and the turbulent kinetic energy are reduced, as well as the north-south temperature gradient within the lake. This temperature gradient depends on the pressuredependent freezing point at the ice base and is therefore closely related to the ice draft. Note that the temperature gradient varies between about 0.1 and $0.4^{\circ} \mathrm{C}$, depending on the eddy parametrisations, and encompasses the values calculated by Wüest and Carmack $(2000)\left(0.12^{\circ} \mathrm{C}\right)$ and Walsh $(2002)$ $\left(0.13^{\circ} \mathrm{C}\right)$, but is slightly larger than the gradient given in Mayer et al. $(2003)$ $\left(0.08^{\circ} \mathrm{C}\right)$. The temperature gradient at the ice-lake interface, which is shown in Fig. 2, is the largest in the model, as freezing in the southern part of the lake results in stratification of the otherwise vertically well-mixed water column (see Section 3.3). Hence, temperature gradients in deeper layers are much smaller.

Increasing the vertical eddy viscosity, for a given horizontal value (dotted lines in Fig. 2), results in a decrease in the turbulent kinetic energy and freezing area, while the maximum temperature in the southern part of the lake is slightly increased. For a decreased vertical viscosity the effects are opposite (dashed lines in Fig. 2). The impact of the ratio between the horizontal and vertical viscosity increases with larger viscosities.

Within the range of parameters tested, the circulation regime is generally stable, but small values $\left(A_{h}^{M} \lesssim 5 \mathrm{~m}^{2} / \mathrm{s}\right)$ result in numerically induced noisy flow patterns (not shown), while large values lead to a breakdown of the transport. Therefore, we choose moderate values of $A_{h}^{M}=20 \mathrm{~m}^{2} / \mathrm{s}$ and $A_{v}^{M}=0.1 \mathrm{~cm}^{2} / \mathrm{s}$ for further studies. These should be considered as the optimised choice between resolving small scale flow patterns and realistic water transport as discussed in Section 3.3. In Fig. 2 the results from using this parameter set are indicated by additional black circles.

Further studies with velocity-dependent mixing schemes, such as the Smagorinsky scheme for along- $\sigma$-layer viscosity (e.g., Smagorinsky, 1963; Haidvogel and Beckmann, 1999; Griffies, 2004) and a Richardson-numberdependent scheme for vertical friction (Pacanowski and Philander, 1981; Haidvogel and Beckmann, 1999), have led to the conclusion that these closure schemes offer no advantages simulating the flow regime in Lake Vostok. The necessary background viscosity dominates the velocity-dependent quantum; hence, constant eddy parameters for viscosity and diffusion are sufficient. 


\subsection{Impact of the Prandtl number}

Fig. 3a shows that an increasing Prandtl number has a similar impact on the temperatures and the turbulent kinetic energy as the simultaneous increase of viscosity and diffusion (Fig. 2): A breakdown of advection, as well as a massive decrease of the north-south temperature gradient in the ice-lake interface is also seen. The dominance of advection over diffusion leads to an erosion of temperature gradients within the lake. The driving force of density gradients is reduced; hence, there is a breakdown in the transport.

If the horizontal Prandtl number is kept at unity, and only the vertical Prandtl number is increased (Fig. 3b), the turbulent kinetic energy and the freezing area are slightly increased. The temperature minimum, which is located in the northern (vertically well mixed) part of the lake (Fig. 4a and Fig. 5), is barely affected. More dominant vertical advection is most conspicuous in the south, where the stratified water column becomes more and more mixed. Hence, the temperature of the upper layer is reduced, and more supercooled water can freeze at the ice sheet.

\subsection{Defining a standard model configuration}

From our sensitivity studies in Section 3.1, we defined an eddy viscosity of $20 \mathrm{~m}^{2} / \mathrm{s}$ (horizontal) and $0.1 \mathrm{~cm}^{2} / \mathrm{s}$ (vertical) as the best parameters to model the circulation within Lake Vostok based on physical assumptions and the analysis of the resulting flow patterns. From Section 3.2, it follows that the turbulent Prandtl number determines the temperature gradient at the lake's upper boundary layer, the turbulent kinetic energy of the lake, and the freezing area. So far, the only observational evidence which can be used to validate our model results is based on three airborne radar profiles across the lake (Siegert et al., 2000), roughly indicating the northern extent of the freezing area. In the absence of better measurements, it follows from Fig. 3 that neither advection nor conduction can be identified as playing a dominant role in Lake Vostok. Hence, a turbulent Prandtl number of unity is the most reasonable choice. In Figs. 2 and 3 this setup is indicated by black circles.

Fig. 4a shows the temperatures at the ice-lake interface and Fig. 5 temperature cross-section from south to north. The temperature difference at the ice-lake interface between the northern and southern ends of the lake is about $0.3^{\circ} \mathrm{C}$ and results mainly from the varying ice draft and, therefore, the pressure-dependent freezing point temperature. In most areas, the lake is vertically well-mixed. Only in the southern part, where freezing takes place (Fig. 4b), are the upper layers laterally stratified. Hence, the average north-south temperature gradient below $3,800 \mathrm{~m}$ in depth is only about $0.07^{\circ} \mathrm{C}$ (which is in good agreement with Mayer et al. (2003)). Of the $15.65 \times 10^{3} \mathrm{~km}^{2}$ ice surface above the lake, about $78 \%$ is affected by melting with an average melt rate of about $2 \mathrm{~cm} /$ year. Freezing takes place only in 
an area of about $3,500 \mathrm{~km}^{2}$ in the southern part of the lake with an average value of about $3 \mathrm{~cm} /$ year, reaching $7 \mathrm{~cm} /$ year in the area of Vostok Station at the south-eastern tip of the lake.

The vertically integrated mass transport stream function (Fig. 6a) indicates that the northern basin of Lake Vostok contains a weak anti-clockwise circulation of about $5 \mathrm{mSv}$, while two stronger gyres (one clockwise and one anticlockwise) each of about $25 \mathrm{mSv}$, occupy the southern basin. Further insight into the circulation within Lake Vostok can be obtained from crosssections, showing the zonal (Fig. 7a) and meridional velocities (Fig. 7b). A highly baroclinic flow and a horizontal shear zone in roughly the middle of the water column in both basins is shown in Fig. 7. Direction and strength of the flow in the upper and lower boundary layers are shown in Figs. 4b and $6 \mathrm{~b}$. In the south, where freezing takes place, two opposing gyres occupy the water column; in the upper half, an anti-cyclonic gyre and below, a cyclonic gyre. From Fig. 6a it follows that the anti-cyclonic gyre is more dominant with respect to the overall mass transport. In the northern half of the southern basin, mass is transported south-eastward along the lake's bottom, rises there, and is transported north-westward (backwards) in the upper half of the water column. For a feature like this, occupying an entire water column, we use the term convection roll from now on. Together with the lower cyclonic structure in the south, this leads to the strongest upwelling within the lake, with velocities up to $25 \mu \mathrm{m} / \mathrm{s}$ at about $253.5^{\circ} \mathrm{W}$, $77.75^{\circ} \mathrm{S}$ (Fig. 6b). The northern basin contains a weaker convection roll with opposite flow direction. In general, upwelling is concentrated in the eastern part of the lake, while downwelling mostly takes place in the west (Fig. 6b). An exception is the southern tip of the lake, where freezing leads to a vertical stratification of the water column and upwelling is concentrated in the west.

\section{Discussion and conclusion}

Based on an improved version of our numerical flow model and using realistic bathymetry and ice thickness, we can show that the circulation within Lake Vostok is baroclinic and divided into three parts: In the northern basin, a weak $(5 \mathrm{mSv})$ convection roll transports water north-eastward along the base of the lake and in the opposite direction along the ice-lake interface. In the northern part of the main basin, a stronger $(25 \mathrm{mSv})$ convection roll transports sub-surface water towards the ridge, while bottom waters flow south-eastward, reaching, close to $253.5^{\circ} \mathrm{W}, 77.75^{\circ} \mathrm{S}$, a cyclonic gyre. This gyre occupies the lower part of southern Lake Vostok, where freezing takes place. This results in the strongest upwelling with velocities up to $25 \mu \mathrm{m} / \mathrm{s}$. The anti-cyclonic gyre, which fills the upper part of the southern water column, dominates; hence, the overall vertically integrated mass transport stream function in this area is anti-cyclonic. In this respect, our model results for the southern basin show a flow pattern comparable to that reported 
by Mayer et al. (2003), who applied a more coarsely resolved flow model to a single-basin Lake Vostok bathymetry (compare Fig.1).

With average vertical velocities of the order of $10 \mu \mathrm{m} / \mathrm{s}$ and a water column thickness of about $800 \mathrm{~m}$, it is possible to estimate the timescale over which a particle travels from the lake bottom to the ice ceiling (or vice versa) to be about 2.5 years. Comparison of the advective vertical velocity with the velocity, based on the diffusive timescale $\left(v=2 A_{m}^{v} / L \approx\right.$ $10^{-5} \mathrm{~m}^{2} \mathrm{~s}^{-1} / 800 \mathrm{~m}=0.025 \mu \mathrm{m} / \mathrm{s}$ ), leads to the conclusion that advection is dominant in the model. From the lake's volume $\left(5.435 \times 10^{3} \mathrm{~km}^{3}\right)$ and the calculated volume flux (about $20 \mathrm{mSv}$ ) we estimate 8.6 years as a horizontal timescale for the mean flow with the standard model configuration. However, this only describes the barotropic part of the circulation, which has been shown to depict strong vertical shear with opposing circulation in the upper and lower parts of the lake.

At present, only indirect observations of the areal extent of active freezing in the southern part of Lake Vostok are available. According to Siegert et al. (2000) it seems likely that freezing takes place south of about $77.6^{\circ} \mathrm{S}$. This would lead to a slightly larger freezing area than the $3,500 \mathrm{~km}^{2}$ modelled with the standard configuration in this study. However, the size of the modelled freezing area depends on the values chosen for sub-gridscale mixing in the model. Different eddy coefficients for viscosity and diffusivity could produce freezing areas between $3,000 \mathrm{~km}^{2}$ and $5,500 \mathrm{~km}^{2}$ (Fig. 2 and 3). Future measurements, in connection with these sensitivity studies, will narrow the parameter space for modelling Lake Vostok. The average freeze rate in the area upstream of Vostok Station can be calculated from the known $210 \mathrm{~m}$ of accreted ice below the station (Jouzel et al., 1999; Siegert et al., 2001) and the travel time of the Vostok core trajectory from the lake's margin to the drill hole. Referring to radar measurements, the length of the trajectory is about $15 \mathrm{~km}$, corresponding to a travel time of 5,000 years (Kwok et al., 2000; Siegert et al., 2001); referring to structure tracking, the trajectory is either 49 or $60 \mathrm{~km}$ long (Bell et al., 2002), corresponding to a travel time of 16,000 to 20,000 years. Hence, the average freeze rate would be between 1.1 and $4.2 \mathrm{~cm} /$ year along the trajectory. However, these values are based on the assumption of an average ice movement of about $3 \mathrm{~m} /$ year. Considering a wider range of velocities from 2 to $4.2 \mathrm{~m} /$ year (Kwok et al., 2000; Wendt, 2005), the calculated freezing rates range from 0.7 to $6 \mathrm{~cm} /$ year. From the analysis of radar studies, Siegert et al. (2000) derived a basal accumulation rate of $2 \mathrm{~cm} /$ year in the northern part of the freezing area and up to $6 \mathrm{~cm} /$ year in the southern tip of the lake. This spatial variation coincides with the modelled freezing pattern (Fig. 4b), which produces an average freezing rate of about $3 \mathrm{~cm} /$ year. However, in the area of Vostok Station, the modelled freezing is significantly higher $(7.4 \mathrm{~cm} /$ year $)$ and exceeds lower limits for this location, derived by Bell et al. (2002) $(0.7 \mathrm{~cm} /$ year $)$ from mass balance or by Salamatin (2000) $(1.1 \mathrm{~cm} /$ year $)$ from energy balance considerations. If the thermal heat flux into the ice is increased by $40 \%$ to $46 \mathrm{~mW} / \mathrm{m}^{2}$, as proposed by Siegert (2005), the modelled average freezing 
rate is increased by only about $1 \%$, while the freezing area is decreased by $1 \%$. A larger impact is found through consideration of the thermal heat flux in freezing areas as well as in melting areas. This leads to a reduction in the average freezing of about $17 \%$ while the freezing area is increased by $11 \%$.

In most areas, the lake is vertically well-mixed, and the temperature gradient between the northern $\left(-3.07^{\circ} \mathrm{C}\right)$ and southern (about $-3.00^{\circ} \mathrm{C}$ ) ends of the lake is about $0.07^{\circ} \mathrm{C}$. This is in good agreement with Mayer et al. $(2003)\left(0.08^{\circ} \mathrm{C}\right)$, but slightly below the values derived by Wüest and Carmack $(2000)\left(0.13^{\circ} \mathrm{C}\right)$ and Walsh $(2002)\left(0.12^{\circ} \mathrm{C}\right)$ using their idealised model setups. Only in the southern part of Lake Vostok, where freezing takes place, is the upper part of the water column stabilised because heat is released into the water. Hence, the water column is laterally stratified in this area, maintaining a strong depth dependence of the north-south temperature gradient. This pool of slightly warmer and stably stratified water suggested by Wüest and Carmack (2000) is found to be about $300 \mathrm{~m}$ thick and occupies about $10 \%$ of the lake's volume.

In all experiments, the basal mass loss from the ice sheet is constantly $5.6 \mathrm{~mm} /$ year (equivalent to a fresh water flux of $2.78 \mathrm{~m}^{3} / \mathrm{s}$, or a basal ice loss of $0.09 \mathrm{~km}^{3} /$ year). This imbalance indicates either a constant growth of the lake or a regular (or periodical) discharge of the lake, as proposed by Wingham et al. (2006) and Fricker et al. (2007) from satellite altimetry for other subglacial lake systems.

In this study we analysed different parameter settings for application of an ocean model to the modelling of the circulation and temperature regime in subglacial Lake Vostok. Further studies will include sensitivity experiments to study the impact of varying salinities and geothermal heat fluxes on Lake Vostok's flow regime, as well as employing open boundary conditions to allow constant mass gain and loss at prescribed lateral boundaries. Finally, this model is suitable for application to other subglacial Antarctic lakes, e.g., $90^{\circ} \mathrm{E}-$ Lake (Bell et al., 2006) which is the second largest subglacial lake identified in Antarctica.

Acknowledgements: This work was funded by the DFG grant MA33471-2. The authors wish to thank M. Studinger for providing us with the lake's geometric data; J. Lieser, who implemented the data into the model and carried out first model runs; Andrea Bleyer for proof reading; Martin Losch and Jill Nicola Schwarz for feedback on an earlier version of the text; and two anonymous reviewers for helpful suggestions which improved the manuscript.

\section{References}

Bell, R. E., Studinger, M., Fahnenstock, M. A., Shuman, C. A., 2006. Tectonically controlled subglacial lakes on the flanks of the Gamburtsev Subglacial Mountains, East Antarctica. Geophys. Res. Lett. 33, L02504, doi:10.1029.2005GL025207. 
Bell, R. E., Studinger, M., Tikku, A. A., Clarke, G. K. C., Gutner, M. M., Meertens, C., 2002. Origin and fate of Lake Vostok water frozen to the base of the East Antarctic ice sheet. Nature 416, 307-310.

Bryan, K., 1969. A numerical method for the study of the circulation of the world ocean. J. Comp. Phys. 4, 347-376.

Cox, M. D., 1984. A primitive equation, three-dimensional model of the ocean. Tech. Rep. GFDL Ocean Group Technical Report No. 1, Princeton University.

Cox, M. D., Bryan, K., 1984. A numerical model of the ventilated thermocline. J. Phys. Oceanogr. 14.

Duxbury, N. S., Zotikov, I. A., Nealson, K. H., Romanovsky, V. E., Carsey, F. D., 2001. A numerical model for an alternative origin of Lake Vostok and its exobiological implications for Mars. J. Geophys. Res. 106 (E1), $1453-1462$.

Ezer, T., Mellor, G. L., 1997. Simulations of the atlantic ocean with a free surface sigma coordinate ocean model. J. Geophys. Res. 102 (C7), 1564715657.

Ezer, T., Mellor, G. L., 2000. Sensitivity studies with the North Atlantic sigma coordinate Princeton Ocean Model. Dyn. Atmos. Oceans 32, 185208.

Ezer, T., Mellor, G. L., 2004. A generalized coordinate ocean model and a comparison of the bottom boundary layer dynamics in terrain-following and in $z$-level grids. Ocean Modelling 6, 379-403.

Fofonoff, N. P., Millard, R. C., 1983. Algorithms for computation of fundamental properties of seawater. UNESCO Technical papers in marine science $44,29$.

Fricker, H. A., Scambos, T., Bindschadler, R., Padman, L., 2007. An active subglacial water system in west Antarctica mapped from space. Science 315 (5818), 1544-1548, doi: 10.1126/science.1136897.

URL http://www . sciencemag. org/cgi/content/abstract/315/5818/1544

Gerdes, R., 1993. A primitive equation ocean circulation model using a general vertical transformation. Part 1: Description and testing of the model. J. Geophys. Res. 98 (C8), 14683-14701.

Griffies, S. M., 2004. Fundamentals of ocean climate models. Princeton University Press, Princeton.

Grosfeld, K., Gerdes, R., Determann, J., 1997. Thermohaline circulation and interaction beneath ice shelf cavities and the adjacent open ocean. J. Geophys. Res. 102 (C7), 15595-15610.

Haidvogel, D. B., Beckmann, A., 1999. Numerical ocean circulation modeling. Imperial Collage Press, London.

Jackett, D. R., McDougall, T. J., 1995. Minimal adjustment of hydrographic profiles to achieve static stability. J. Atmos. Ocean. Technol. 12, 381-389.

Jouzel, J., Petit, J. R., Souchez, R., Barkov, N. I., Lipenkov, V. Y., Raynaud, D., Stievenard, M., Vassiliev, N. I., Verbeke, V., Vimeux, F., 1999. More than 200 meters of lake ice above subglacial Lake Vostok, Antarctica. Science 286, 2138-2141, doi: 10.1126/science.286.5447.2138. 
Kwok, R., Siegert, M. J., Carsey, F. D., 2000. Ice motion over Lake Vostok, Antarctica: constraints on inferences regarding the accreted ice. J. Glaciol. 46, 689-694.

Ly, L. N., Jiang, L., 1999. Horizontal pressure gradient errors of the monterey bay sigma coordinate ocean model with various grids. Journal of Oceanography 55, 87-97.

Maule, C. F., Purucker, M. E., Olsen, N., Mosegaard, K., Jul. 2005. Heat Flux Anomalies in Antarctica Revealed by Satellite Magnetic Data. Science 309, 464-467, doi: 10.1126/science.1106888.

Mayer, C., Grosfeld, K., Siegert, M., 2003. Salinity impact on water flow and lake ice in Lake Vostok, Antarctica. Geophys. Res. Lett. 30 (14), 1767, doi:10.1029/2003GL017380.

Mellor, G. L., Blumberg, A. F., 1985. Modeling vertical and horizontal diffusivities with the sigma coordinate system. Mon. Wea. Rev. 113, 13791383.

Pacanowski, R. C., Philander, S. G. H., 1981. Parameterization of vertical mixing in numerical models of the tropical oceans. J. Phys. Oceanogr. 11, 1443-1451.

Pattyn, F., de Smedt, B., Souchez, R., 2004. Influence of subglacial Vostok lake on the regional ice dynamics of the Antarctic ice sheet: a model study. J. Glaciol. 50 (171), 583-589.

Salamatin, A. N., 2000. Paleoclimatic reconstructions based on borehole temperature measurements in ice sheets. Possibilities and limitations. In: Hondoh, T. (Ed.), Physics of Ice Core Records. Hokkaido Univ. Press, Sapporo, Japan, pp. 243-282.

Siegert, M. J., 2005. Lakes beneath the ice sheet: The occurrence, analysis and future exploration of Lake Vostok and other Antarctic subglacial lakes. Annu Rev Earth Pl Sc 33, 215-245, doi: 10.1146/annurev.earth.33.092203.122725.

Siegert, M. J., Ellis-Evans, J. C., Tranter, M., Mayer, C., Petit, J.-R., Salamatin, A., Priscu, J. C., 2001. Physical, chemical and biological processes in Lake Vostok and other Antarctic subglacial lakes. Nature 414, 603-609.

Siegert, M. J., Kwok, R., Mayer, C., Hubbard, B., 2000. Water exchange between the subglacial Lake Vostok and the overlying ice sheet. Nature 403, 643-646, doi: 10.1038/35001049.

Smagorinsky, J., 1963. General circulation experiments with the primitive equations: I. the basic experiment. Mon. Wea. Rev. 91, 99-164.

Studinger, M., Bell, R. E., Tikku, A. A., 2004. Estimating the depth and shape of subglacial Lake Vostok's water cavity from aerogravity data. Geophys. Res. Lett. 31 (L12401), doi:10.1029/2004GL019801.

Thoma, M., Grosfeld, K., Lange, M. A., 2006a. Impact of the Eastern Weddell Ice Shelves on water masses in the eastern Weddell Sea. J. Geophys. Res. 111 (C12010), doi:10.1029/2005JC003212.

Thoma, M., Grosfeld, K., Lange, M. A., 2006b. The impact of mixing parameterisation and bathymetry filtering on the simulated hydrography along steep continental shelf regions in terrain following ocean models. 
FRISP Report 17.

URL http://web.gfi.uib.no/\%7Engfls/frisp/Rep17/thoma05.pdf

Walsh, D., 2002. A note on eastern-boundary intensification of flow in Lake Vostok. Ocean Modelling 4, 207-218.

Weaver, A. J., Sarachik, E. S., 1990. On the importance of vertical resolution in certain ocean general circulation models. J. Phys. Oceanogr. 20, 600609 .

Wendt, A., 2005. Untersuchungen zu gezeitenbedingten Höhenänderungen des subglazialen Lake Vostok, Antarktika. Berichte zur Polar und Meeresforschung 511.

Williams, M. J. M., 2001. Application of a three-dimensional numerical model to Lake Vostok: An Antarctic subglacial lake. Geophys. Res. Lett. $28(3), 531-534$.

Wingham, D. J., Siegert, M. J., Shepherd, A., Muir, A. S., 2006. Rapid discharge connects Antarctic subglacial lakes. Nature 440 (C6), 10331036, doi:10.1038nature04660.

Wüest, A., Carmack, E., 2000. A priori estimates of mixing and circulation in the hard-to-reach water body of Lake Vostok. Ocean Modelling 2 (1), $29-43$.
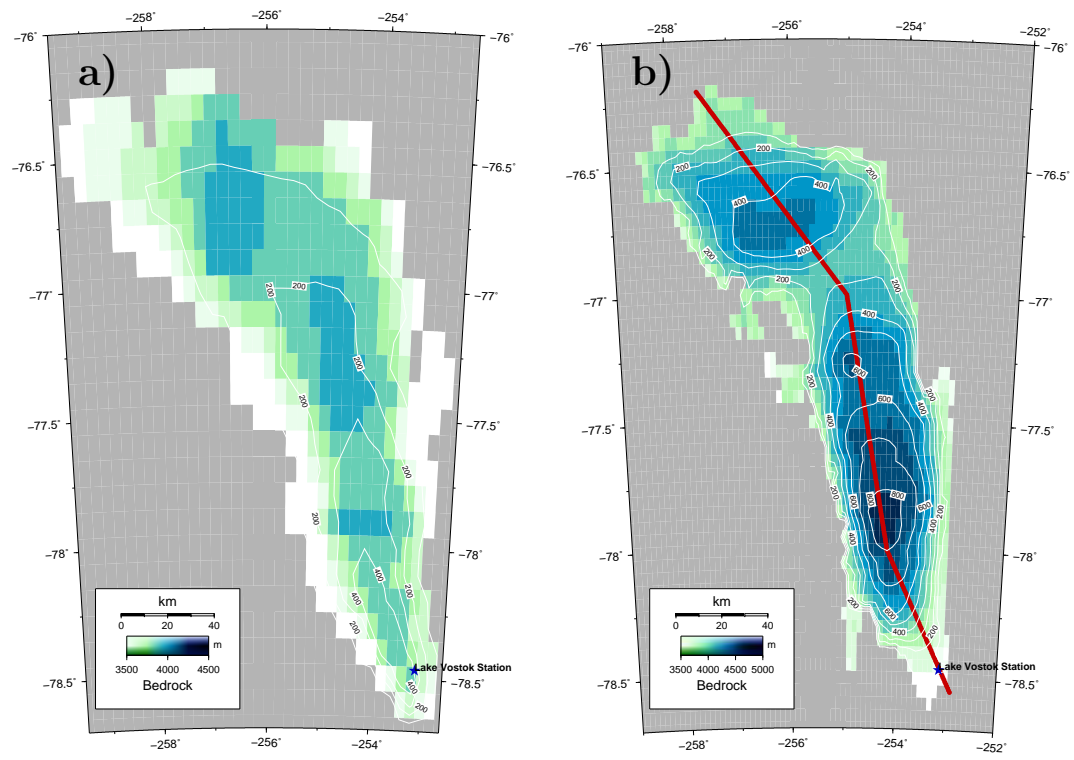

Fig. 1 Bedrock topography of Lake Vostok (a) as used in Mayer et al. (2003) and (b) used in this study, provided by Studinger et al. (2004). The water column thickness is shown as contours. The red line indicates a profile transect and the blue star indicates the position of the Russian Vostok research station. 


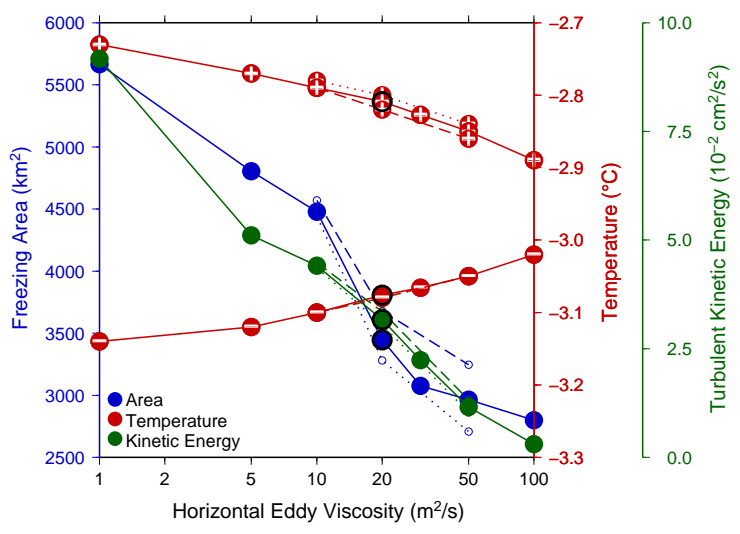

Fig. 2 Freezing area (blue), ice-lake interface temperature (red), and turbulent kinetic energy (green) as a function of different values for horizontal viscosities. For temperature, maximum (plus signs) and minimum (minus signs) are indicated. The vertical eddy viscosity is $2 \times 10^{6}$ (solid line), $1 \times 10^{6}$ (dotted line), or $4 \times 10^{6}$ (dashed line) smaller than the value of the horizontal coefficient. The Prandtl numbers are kept to unity. Black circles indicate the standard model configuration.
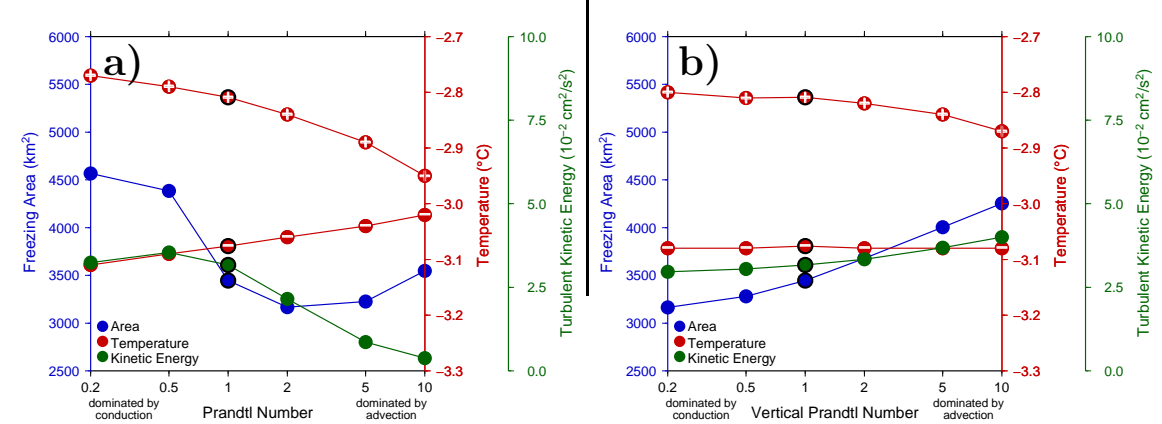

Fig. 3 a) As for Fig. 2, but for constant eddy viscosities of $A_{h}^{M}=20 \mathrm{~m}^{2} / \mathrm{s}$ and $A_{v}^{M}=0.1 \mathrm{~cm}^{2} / \mathrm{s}$. The abscissa indicates the value of the vertical and horizontal Prandtl numbers, which are kept identical.

b) As for Fig. 3a, but for a horizontal Prandtl number of unity and a varying vertical Prandtl number. 


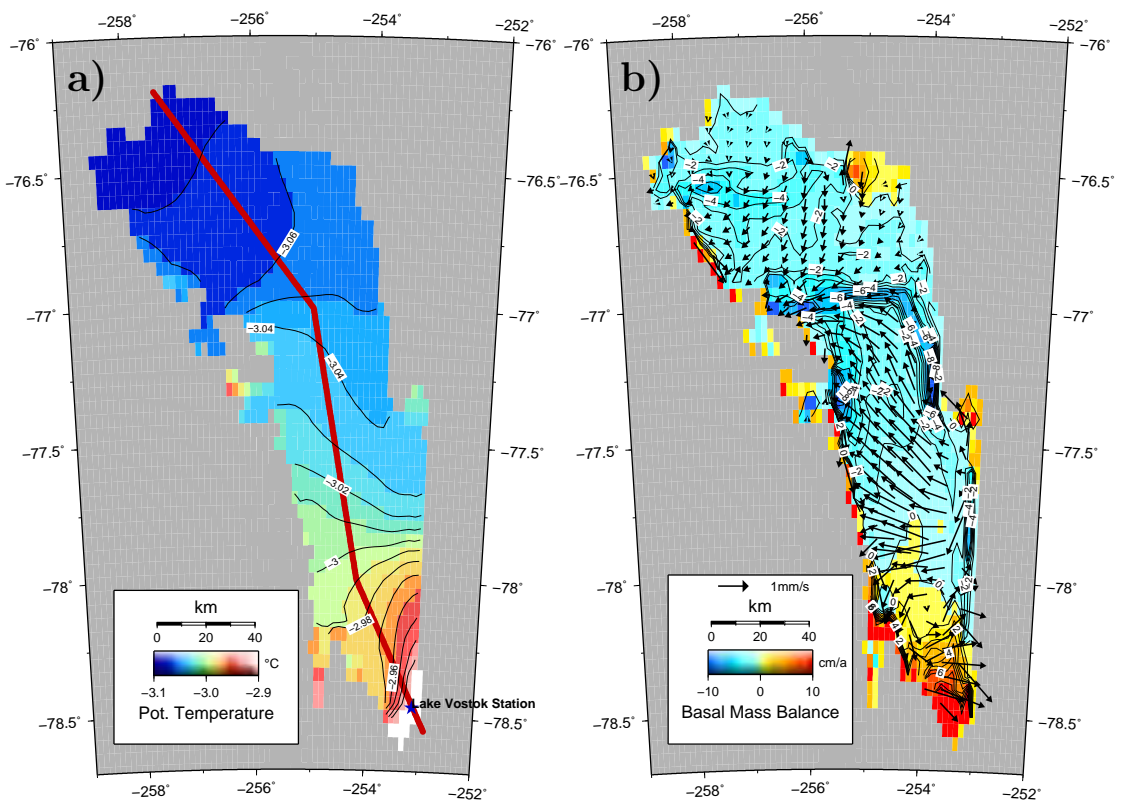

Fig. 4 a) Modelled temperatures at the ice-lake interface.

b) Modelled basal mass balance at the ice-lake interface. Negative values (blue/green) indicate melting, positive (yellow/red) values freezing. Velocities in the ice-lake boundary layer are indicated by arrows.

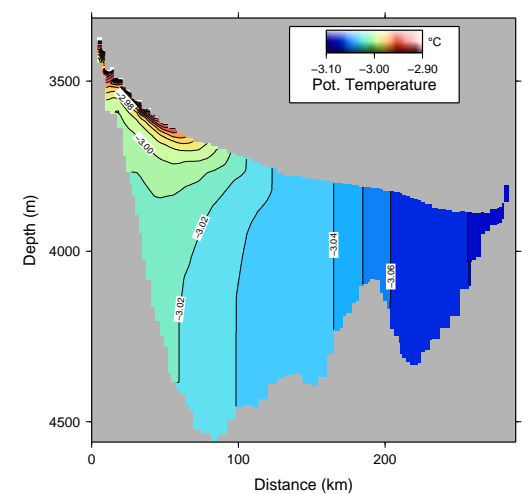

Fig. 5 Temperature cross-section from south to north indicated in Fig. 4a). 


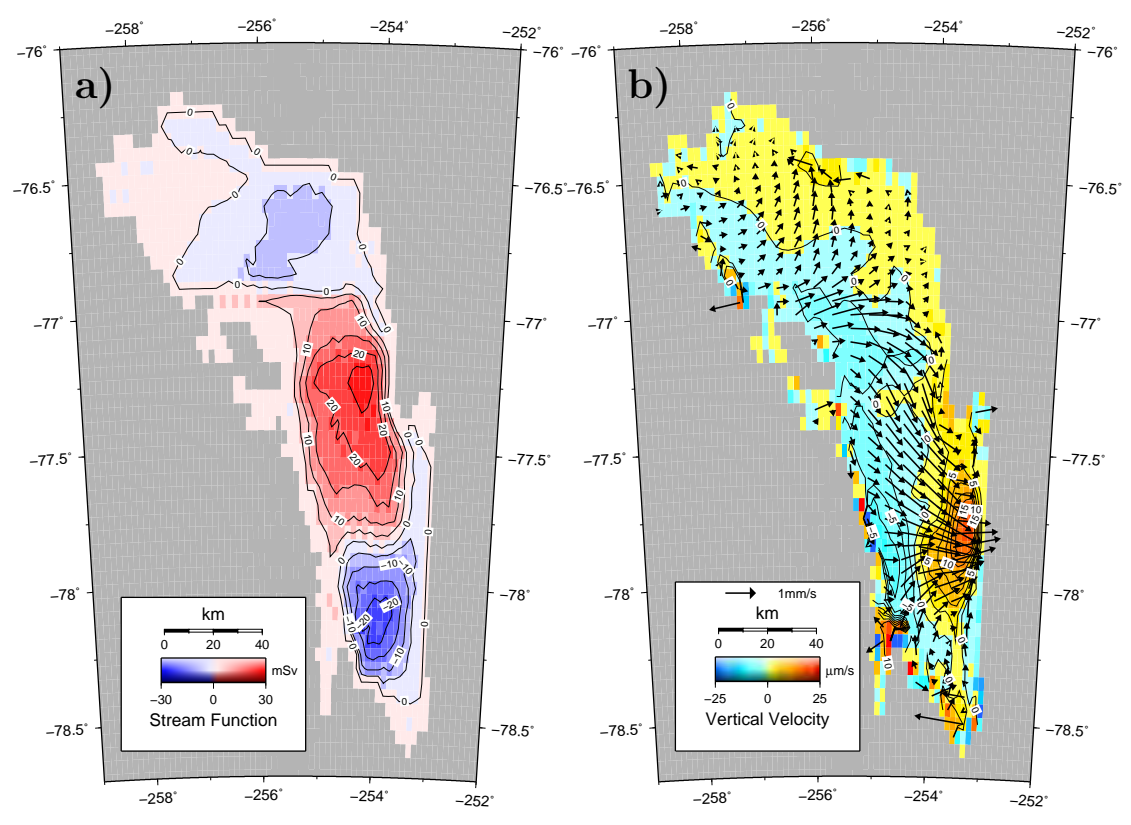

Fig. 6 a) Vertically integrated mass transport stream function $(1 \mathrm{mSv}=$ $10^{3} \mathrm{~m}^{3} / \mathrm{s}$ ).

b) Integrated vertical velocity, arrows indicate the flow in the lake's bottom layer.
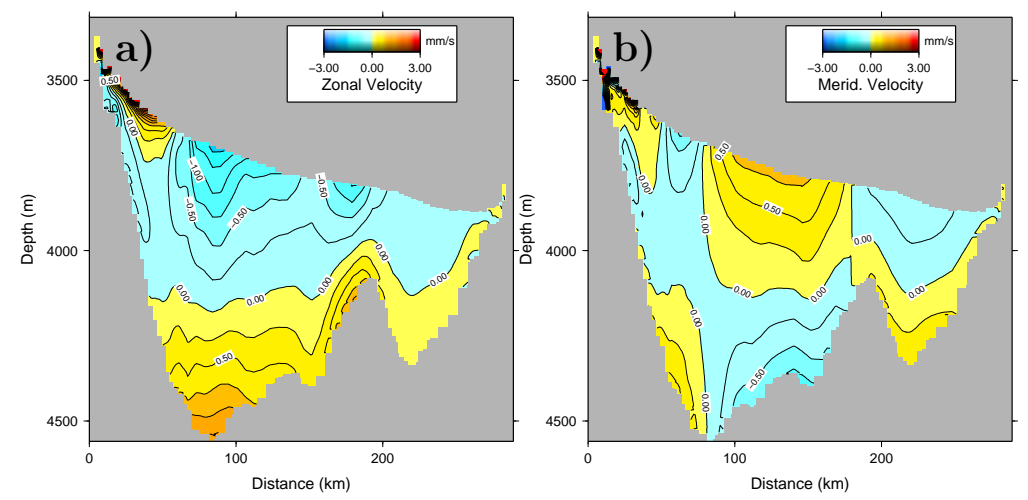

Fig. 7 Zonal (a) and meridional (b) velocities along the track shown in Fig. 6a). 